\title{
Erratum to "Effects of particle size and dry matter content of a total mixed ration on intraruminal equilibration and net portal flux of volatile fatty acids in lactating dairy cows” (J. Dairy Sci. 93:4223-4238)
}

\section{A. C. Storm and N. B. Kristensen}

An error was made in calculation of the flux data presented in this paper. Fluxes are presented as wholeblood fluxes but, because of a programming error, are, in fact, plasma fluxes. The errors do not, in general, affect the conclusions of the paper. The corrected text and tables are presented below, with corrections in bold font. The authors apologize for this error.

Storm, A. C., and N. B. Kristensen. 2010. Effects of particle size and dry matter content of a total mixed ration on intraruminal equilibration and net portal flux of volatile fatty acids in lactating dairy cows. J. Dairy Sci. 93(9):4223-4238.

Abstract (page 4223):

Consequently, reduced FPS affected the intraruminal equilibration of VFA between mat and ventral rumen with an estimated turnover rate of isobutyrate increasing from $\mathbf{6 6} \pm 3 \% / \mathrm{h}$ with long particles to $\mathbf{8 1} \pm 3 \% / \mathrm{h}$ with short particles.

Results: (pages 4230-4231):

\section{Net Portal Fluxes}

Net portal blood flux of oxygen, carbon dioxide, and net portal plasma flux of glucose, L-lactate, and BHBA were not affected by treatment or time $(\boldsymbol{P}=\mathbf{0 . 1 5}$ to $\mathbf{0 . 8 3}$; Table 7). The net uptake of oxygen in the PDV was on average $\mathbf{2 , 1 3 4} \pm \mathbf{5 8} \mathbf{~ m m o l} / \mathbf{h}$. The corresponding net release of carbon dioxide from the PDV was $\mathbf{2 , 5 9 1} \pm 353 \mathrm{mmol} / \mathbf{h}$. There was PDV release of glucose from 0.5 to $1.5 \mathrm{~h}$ after feeding and net uptake was observed outside this time period.

The net portal blood fluxes of all VFA increased $(P$ $<0.01$ ) after feeding. The net portal blood flux of total VFA was on average $4,113 \pm 119 \mathrm{mmol} / \mathrm{h}$ and increased from 3,256 to $5,012 \pm 322 \mathrm{mmol} / \mathrm{h}$ from $0.5 \mathrm{~h}$ before to $2.5 \mathrm{~h}$ after feeding. There were no effects of treatments on net portal fluxes of VFA $(\boldsymbol{P}=$ 0.25 to 0.99 ).

\section{Net Hepatic Fluxes}

Net hepatic blood flux of carbon dioxide, acetate, and the net hepatic plasma flux of glucose were not affected by treatments or time $(\boldsymbol{P}=\mathbf{0 . 2 8}$ to $\mathbf{0 . 9 9}$; Table 7). The net hepatic blood fluxes of oxygen, propionate, butyrate, isobutyrate, valerate, isovalerate, caproate, and net hepatic plasma fluxes of L-lactate and BHBA increased after feeding $(P<0.01$ to 0.02$)$. The net hepatic flux of glucose was on average $645 \pm 19$ $\mathrm{mmol} / \mathrm{h}$ and was not affected by time $(P=0.31)$. The net hepatic uptake of L-lactate, propionate, isobutyrate, and valerate relative to the net hepatic production of glucose was $25.4 \pm 2.2,69.5 \pm 3.3,2.3 \pm 0.09$, and $\mathbf{4 . 1} \pm \mathbf{0 . 2 5 \%}$, respectively, accounting for $>98 \%$ of hepatic glucogenic precursors on a net basis.

\section{Medial Ruminal Turnover and Fractional Absorption Rates of VFA}

The turnover of the medial ruminal isobutyrate pool calculated from the net portal flux of isobutyrate and the medial ruminal isobutyrate pool increased $15.4 \pm$ 4.6 percentage units/h from 66 to $81 \pm 3 \% / h(P=$ 0.01 ) with decreasing total ruminal pool (Table 8 ). The same trends were observed for medial turnover of acetate and butyrate $(\boldsymbol{P}=\mathbf{0 . 0 6})$. An FDM $\times$ time interaction affected the values of propionate, butyrate, and isobutyrate $(P=0.01, \mathbf{0 . 0 4}$, and 0.02 , respectively $)$, all higher before feeding with dry diets. The FDM did not affect ( $\boldsymbol{P}$ $=0.26$ to 0.49 ) the medial ruminal pool turnover.

Even though the turnover rate of the medial pool of isobutyrate increased with short particles, no effects of treatments were observed for the CFAR from the ventral pool of isobutyrate, acetate, propionate, or butyrate. Nor were there observed time effects for acetate, propionate, butyrate, and isobutyrate corrected ventral rumen fluid fractional absorption rates.

\section{Clearance of Ruminal VFA and Intraruminal Fluid Flow}

The intraruminal flow of fluid through the medial mat was $142 \pm 30 \mathrm{~L} / \mathrm{h}$ and not affected by dietary treatments or time $(\boldsymbol{P}=\mathbf{0 . 3 2}$ and $\mathbf{0 . 5 4}$, respectively; data not shown). The clearance of ruminal acetate from the medial to ventral ruminal pool was on average $\mathbf{4 4 . 2}$ $\pm 1.1 \mathrm{~L} / \mathrm{h}$ and was not affected by dietary treatments 
or time (Table 8). The medial to ventral pool clearance of propionate, butyrate, and isobutyrate was on average $38.6 \pm 1.0,43.6 \pm 1.4$, and $33.2 \pm 0.8 \mathrm{~L} / \mathrm{h}$, respectively. Medial butyrate clearance increased $(P<$ 0.01 ) from 34.1 to $48.4 \pm \mathbf{3 . 2} \mathrm{L} / \mathrm{h}$ after feeding. The medial clearance of propionate and isobutyrate were affected by an FDM $\times$ time interaction $(P=0.02$ and 0.04 , respectively), reflecting greater clearance with dry diets before feeding.

Ventral pool to blood clearances of acetate, propionate, butyrate, and isobutyrate were not affected ( $\boldsymbol{P}$ $=0.23$ to 0.89 ) by treatments and were on average $65.7 \pm 2.1,59.1 \pm 2.0,66.9 \pm 2.5$, and $49.2 \pm$ $1.6 \mathbf{L} / \mathbf{h}$, respectively. The ventral pool clearance of butyrate increased $(P<0.01)$ from 43.7 to $\mathbf{7 6 . 4} \pm$ $5.7 \mathrm{~L} / \mathrm{h}$ after feeding.

\section{Discussion (pages 4236-4237):}

Rate of reticuloruminal VFA absorption relies on the rate at which VFA are supplied from the ruminal mat to the reticulorumen epithelia. Because of the large volume of the rumen, the cow cannot rely on passive diffusion to facilitate the intraruminal equilibration. The mixing of ruminal contents through ruminal motility is therefore crucial for effective VFA absorption. Controlling the reticulorumen motility may be a route for the cow to control VFA absorption. In acute ruminal acidosis, the frequency of primary reticuloruminal contractions is reduced or even absent, reducing the mixing and passage of ruminal content to the omasum (Crichlow, 1988). Through this action, the cow may affect the rate at which ruminal VFA flows from the medial to the ventral pool and consequently downregulate the absorption of VFA from the reticulorumen. The FPRC was not affected by dietary treatments in the present study; however, because of the reduced ruminal mat together with the shorter particles, the relative movement of ruminal fluid by the contractions might increase, affecting the intraruminal equilibration of VFA. With the setup used we cannot measure the amplitude of the contractions and therefore cannot account for any frequency $\times$ amplitude (work) effect. However, the flow from the medial to the ventral pool $(142 \pm 30 \mathrm{~L} / \mathrm{h})$ of ruminal fluid was not affected by the size of the medial pool. Thus, intraruminal fluid flow and thereby intraruminal VFA flow seems not to be dependent on the size of the ruminal mat.

The overall values of net portal flux of VFA were in agreement with previous studies using dairy cows receiving corn silage-based rations with the same DMI as in the present study (Kristensen and Raun, 2007). Changing the physical characteristic of the ruminal mat was expected to affect the rate of fermentation and intraruminal turnover, consequently affecting the net portal flux of VFA; however, this was not observed. The best estimate of corrected absorption was evaluated to be isobutyrate because of the limited PDV metabolism and high portal blood recovery of ruminal infused isobutyrate (Kristensen and Harmon, 2004b). Isobutyrate was therefore evaluated to be the best VFA marker in relation to intraruminal turnover and corrected flux using the ruminal VFA model (Figure 2). The model is constructed under the assumption that VFA is primarily absorbed from the ventral ruminal pool and that VFA equilibrates from the medial mat to the ventral pool with the same rate that VFA is absorbed. The experimental design enables us to measure the real time dynamic of VFA between ruminal pools and the VFA exchange between ventral ruminal pool and portal blood. The ruminal CFAR links the corrected flux of specific metabolites to the ruminal pool of interest, thereby describing the pool turnover rate. The CFAR of the total pool of VFA has previously been studied in vivo under intact (Krehbiel et al., 1995; Resende Júnior et al., 2006; Penner et al., 2009) and washed (Dijkstra et al., 1993; Kristensen and Harmon, $2004 a, b)$ rumen conditions. The present study used ventral ruminal pool and corrected flux to estimate the CFAR and can therefore not directly be related to these studies. No effect ( $P=\mathbf{1 7}$ to $\mathbf{0 . 9 5})$ was revealed when calculating the CFAR of acetate, propionate, butyrate, and isobutyrate $(430 \pm 17,392 \pm 17,426 \pm 17$, and $324 \pm 12 \% / h$, respectively) because the ventral ruminal pool and corrected flux of these metabolites were not affected by dietary treatments. However, the effect of FPS on the medial pool of isobutyrate was clear when calculating the intraruminal turnover. The turnover of isobutyrate increased $(\boldsymbol{P}<\mathbf{0 . 0 1})$ as the medial pool decreased with short particles; the same trend was observed for acetate and butyrate $(\boldsymbol{P}=$ 0.06). This shows that the effect of dietary particle size is related to the turnover of the medial pool and that the size of the mat affects the retention of isobutyrate. It can be hypothesized that this effect is the same for other VFA because the estimated fluid flow through the mat was not affected.

Medial to ventral ruminal clearance and ventral rumen to portal blood clearance of acetate, propionate, butyrate, and isobutyrate were not affected by dietary treatments because no effects were detected on the ruminal concentrations or corrected flux of these metabolites. The clearance describes the VFA dynamic of the rumen in relation to the mixing of ruminal contents and exposure of the VFA to the epithelia for absorption. The medial ruminal clearance of isobutyrate indicates 
that $33.2 \pm 0.8 \mathrm{~L} / \mathrm{h}$ of medial ruminal fluid was cleared of this metabolite, whereas $49.2 \pm 1.6 \mathrm{~L} / \mathrm{h}$ of ventral ruminal fluid was cleared. In relation to the ruminal pool sizes, this indicates the incomplete equilibration of the mat with the ventral ruminal fluid.

Tables (pages 4233-4234):

Table 7. Blood plasma flow in the portal vein, hepatic vein, and hepatic artery and net portal flux and net hepatic flux of oxygen, carbon dioxide, and metabolites in dairy cows fed 2 levels of TMR DM and 2 levels of forage particle size

\begin{tabular}{|c|c|c|c|c|c|c|c|c|c|}
\hline \multirow[b]{2}{*}{ Item } & \multicolumn{2}{|c|}{ Short } & \multicolumn{2}{|c|}{ Long } & \multirow[b]{2}{*}{$\begin{array}{c}\text { SEM } \\
(\mathrm{n}=4)\end{array}$} & \multicolumn{4}{|c|}{$P$-value ${ }^{1}$} \\
\hline & Dry & Moist & Dry & Moist & & FPS & FDM & $\begin{array}{c}\text { FPS } \times \\
\text { FDM }\end{array}$ & Time \\
\hline Portal & 1,433 & 1,262 & 1,322 & 1,335 & 50 & 0.71 & 0.15 & 0.10 & 0.04 \\
\hline Hepatic vein & 1,499 & 1,488 & 1,475 & 1,482 & 69 & 0.83 & 0.98 & 0.90 & 0.01 \\
\hline Hepatic artery & 66 & 226 & 153 & 147 & 63 & 0.95 & 0.25 & 0.22 & 0.71 \\
\hline Carbon dioxide & 3,678 & 2,783 & 2,313 & 1,999 & 612 & 0.14 & 0.37 & 0.70 & 0.62 \\
\hline Acetate & 3,022 & 2,672 & 2,843 & 2,859 & 274 & 0.99 & 0.56 & 0.52 & $<0.01$ \\
\hline Propionate & 942 & 834 & 896 & 862 & 85 & 0.92 & 0.43 & 0.67 & $<0.01$ \\
\hline Butyrate & 276 & 261 & 282 & 262 & 31 & 0.91 & 0.58 & 0.93 & $<0.01$ \\
\hline Isobutyrate & 31.1 & 29.3 & 29.9 & 30.9 & 2.1 & 0.99 & 0.89 & 0.49 & $<0.01$ \\
\hline Valerate & 54.7 & 47.4 & 49.5 & 45.0 & 5.5 & 0.52 & 0.28 & 0.83 & $<0.01$ \\
\hline Isovalerate & 18.3 & 15.5 & 16.3 & 16.7 & 1.4 & 0.79 & 0.42 & 0.29 & $<0.01$ \\
\hline \multicolumn{10}{|c|}{ Net hepatic blood flux, $\mathrm{mmol} / \mathrm{h}$} \\
\hline Oxygen & $-2,334$ & $-2,578$ & $-2,305$ & $-2,287$ & 190 & 0.45 & 0.69 & 0.43 & $<0.01$ \\
\hline Carbon dioxide & 1,725 & 1,174 & 1,862 & 1,592 & 879 & 0.63 & 0.43 & 0.83 & 0.31 \\
\hline Acetate & 10 & 390 & 239 & 159 & 131 & 0.99 & 0.28 & 0.11 & 0.53 \\
\hline Propionate & -871 & -759 & -824 & -795 & 80 & 0.95 & 0.40 & 0.62 & $<0.01$ \\
\hline Butyrate & -220 & -198 & -221 & -207 & 28 & 0.87 & 0.54 & 0.89 & $<0.01$ \\
\hline Isobutyrate & -28.9 & -26.5 & -27.6 & -28.8 & 1.9 & 0.89 & 0.73 & 0.37 & $<0.01$ \\
\hline Valerate & -51.9 & -45.1 & -48.5 & -43.9 & 4.9 & 0.61 & 0.23 & 0.92 & $<0.01$ \\
\hline Isovalerate & -14.6 & -10.3 & -11.0 & -12.0 & 1.7 & 0.60 & 0.36 & 0.16 & $<0.01$ \\
\hline Carproate & -60.9 & -48.5 & -49.8 & -43.6 & 7.5 & 0.30 & 0.25 & 0.67 & $<0.01$ \\
\hline \multicolumn{10}{|c|}{ Net hepatic plasma flux, $\mathrm{mmol} / \mathrm{h}$} \\
\hline Glucose & 701 & 630 & 620 & 631 & 52 & 0.46 & 0.57 & 0.45 & 0.31 \\
\hline L-Lactate & -340 & -297 & -247 & -275 & 49 & 0.27 & 0.89 & 0.49 & 0.01 \\
\hline BHBA & 273 & 298 & 290 & 234 & 44 & 0.60 & 0.76 & 0.38 & 0.02 \\
\hline
\end{tabular}

${ }^{1} \mathrm{FPS}=$ forage particle size $\mathrm{FDM}=$ feed $\mathrm{DM}$; time $=$ sample time $(\mathrm{n}=8)$. 
Table 8. Medial pool turnover, corrected ${ }^{1}$ fractional absorption rate, and corrected ${ }^{1}$ ruminal clearance of VFA in dairy cows fed 2 levels of TMR $\mathrm{DM}$ and 2 levels of forage particle size

\begin{tabular}{|c|c|c|c|c|c|c|c|c|c|}
\hline \multirow[b]{2}{*}{ Item } & \multicolumn{2}{|c|}{ Short } & \multicolumn{2}{|c|}{ Long } & \multirow{2}{*}{$\begin{array}{c}\text { SEM } \\
(\mathrm{n}=4)\end{array}$} & \multicolumn{4}{|c|}{$P$-value ${ }^{2}$} \\
\hline & Dry & Moist & Dry & Moist & & FPS & FDM & $\mathrm{FPS} \times \mathrm{FDM}$ & Time \\
\hline \multicolumn{10}{|c|}{ Medial pool turnover, ${ }^{3 \%} / \mathrm{h}$} \\
\hline Acetate & 114.9 & 98.0 & 89.8 & 85.4 & 8.9 & 0.06 & 0.26 & 0.50 & 0.29 \\
\hline Propionate* & 96.9 & 88.4 & 80.1 & 75.8 & 8.5 & 0.12 & 0.47 & 0.81 & 0.26 \\
\hline Butyrate* & 97.5 & 94.8 & 84.6 & 76.7 & 7.3 & 0.06 & 0.49 & 0.73 & 0.06 \\
\hline Isobutyrate* & 84.3 & 77.9 & 66.6 & 64.8 & 4.6 & $<0.01$ & 0.44 & 0.64 & 0.67 \\
\hline Propionate & 481 & 325 & 410 & 366 & 92 & 0.87 & 0.31 & 0.56 & 0.23 \\
\hline Butyrate & 432 & 334 & 441 & 382 & 52 & 0.60 & 0.17 & 0.71 & 0.36 \\
\hline Isobutyrate & 393 & 272 & 354 & 320 & 58 & 0.95 & 0.20 & 0.47 & 0.86 \\
\hline \multicolumn{10}{|c|}{ Medial to ventral clearance ${ }^{5} \mathrm{~L} / \mathrm{h}$} \\
\hline Acetate & 46.8 & 41.4 & 44.7 & 42.1 & 4.0 & 0.87 & 0.35 & 0.73 & 0.32 \\
\hline Propionate* & 39.6 & 37.3 & 39.6 & 37.3 & 3.5 & 0.99 & 0.53 & 0.99 & 0.58 \\
\hline Butyrate & 39.7 & 40.2 & 43.1 & 37.9 & 4.2 & 0.90 & 0.59 & 0.52 & $<0.01$ \\
\hline Isobutyrate & 56.9 & 45.4 & 47.3 & 45.6 & 5.3 & 0.38 & 0.23 & 0.37 & 0.02 \\
\hline
\end{tabular}

${ }^{1}$ Corrected portal flux of acetate, propionate, butyrate, and isobutyrate (Kristensen and Harmon, 2004a,b).

${ }^{2} \mathrm{FPS}=$ forage particle size; FDM $=$ feed DM; time $=$ sample time $(\mathrm{n}=4)$.

${ }^{3}$ Medial pool turnover $=$ corrected VFA flux/medial ruminal VFA pool.

${ }^{4}$ Corrected fractional absorption rate $(\mathrm{CFAR})=$ corrected VFA flux/ventral ruminal VFA pool.

${ }^{5}$ Medial clearance $=$ corrected VFA flux/medial ruminal concentration of VFA.

${ }^{6}$ Ventral clearance $=$ corrected VFA flux/ventral ruminal concentration of VFA.

$*$ FDM $\times$ time, $P<0.05$ 